\title{
Review on: Folate in Crop Plants
}

\section{K. S. Aiyswaraya ${ }^{1 *}$, R. Saraswathi ${ }^{1}$, S. Ramchander $^{1}$, D. Uma ${ }^{3}$, M. Aswin ${ }^{1}$,} B. N. Rithesh $^{1}$, P. Jeyaprakash ${ }^{1}$, D. Sudhakar ${ }^{4}$ and S. Robin ${ }^{1}$

${ }^{1}$ Department of Rice, Centre for Plant Breeding and Genetics, Tamil Nadu Agricultural University, Coimbatore, Tamil Nadu, India-641003

${ }^{2}$ International Rice research Institute, South Hub, ICRISAT, Patancheru, Hyderabad, India

${ }^{3}$ Department of Plant Biochemistry, Centre for Plant Molecular Biology and Biotechnology, Tamil Nadu Agricultural University, Coimbatore, Tamil Nadu, India-641003

${ }^{4}$ Department of Biotechnology, Centre for Plant Molecular Biology and Biotechnology, Tamil Nadu Agricultural University, Coimbatore, Tamil Nadu, India-641003

*Corresponding author

\section{A B S T R A C T}

\begin{tabular}{l} 
Ke y w o r d s \\
food crop, \\
$\begin{array}{l}\text { Folate, rice } \\
\text { germplasm }\end{array}$ \\
Article Info \\
\hline $\begin{array}{l}\text { Accepted: } \\
\text { 22 February } 2020 \\
\text { Available Online: } \\
10 \text { March } 2020\end{array}$ \\
\hline
\end{tabular}

Rice (Oryza sativa L.) is a major staple food crop for most of world's population but unfortunately with low folate content when compared to other plant based foods. Folate is an essential micronutrient in human diet and its deficiency causes neural tube defects, coronary heart disease and certain forms of cancer, impaired cognitive functions. Hence, screening and evaluation of available rice germplasm accessions for folate content is the basic step to identify folate rich accessions for further studies and mapping of QTLs/genes associated with folate content to improve its content through molecular breeding especially marker assisted selection.

\section{Introduction}

Rice, one of the most important staple food crops and it provides more than 40 per cent of the daily calories for the world population (Parengam et al., 2010). The need for improving rice production status in terms of quality and quantity has been projected as an important task to meet out the projected population of 9 billion by 2050 (Godfray et al., 2010). For people who rely on cereals like rice as staple food, a significant proportion of minerals required for vital metabolic activities of human system should come from these grains. Hence global food and nutritional security relies on the production and nutritional status of rice grain for their bulk caloric intake. After the remarkable progress 
in rice production the next frontier of rice research and development appears to be the grain nutrition quality. This includes rice rich in essential vitamins and minerals such as beta-carotene (pro-vitamin A), Vitamin B complex, iron and zinc.

There are several methods like conventional and molecular approaches to improve the content of these limiting compounds within edible portions of plants. The attempts of so called biofortification or biological supplementation at enhanced levels of synthesis and accumulation of nutrients by plants that are deficient or have normal content of a particular nutrient through conventional breeding.

\section{Hidden hunger}

Micronutrient malnutrition has been recognized as a gigantic and rapidly growing public health problem not only amongst the poor but also across the whole spectrum of people living on an unbalanced diet. Rice (Oryza sativa L.) is a "global grain" cultivated widely across the world and feeds millions of mankind. About 90 per cent of rice produced is consumed in south and southeast Asia, where the normal consumption of rice range from $300 \mathrm{~g}$ to around $800 \mathrm{~g}$ per day per person.

\section{Dimensions of hidden hunger and key players}

The human body extracts 51 different essential compounds from food which it cannot produce itself through metabolism. Among these, are amino acids and around 19 so-called micronutrients (vitamins, trace elements, and minerals), which exert a direct influence on physical and mental development, the immune system and are vital to the body's metabolic processes. To date, the deficiency of only a certain few micronutrients in the human body is known by means of clinical symptoms, such as scurvy (due to a lack of vitamin $\mathrm{C}$ ), rickets (caused by a vitamin $\mathrm{D}$ deficiency), beriberi (triggered by too little vitamin B) and pellagra (resulting from a niacin deficiency). Thus, hidden hunger is mostly described in terms of lack of vitamins, iron, zinc and iodine which are the key players. This does not exclude the possibility that the micronutrients which have hitherto been the object of less concern also have a major impact on our susceptibility to certain illnesses or the onset of such ailments in later life.

It may not be surprising that new candidates will be added to the list of key players in the near future as already folic acid, Vitamin D and Vitamin $\mathrm{B}_{12}$ are in the wait list.

\section{Role of vitamins in human nutrition}

Vitamin deficiencies cause diseases that can be severe and even lethal in some cases. For instance, vitamin B deficiency is a major health problem in low-resource countries, putting an estimated 125 to 130 million children at increased risk of morbidity and mortality from infectious diseases (Kraemer et al., 2008). In much of the developed world such deficiencies are however rare due to an adequate supply of food and/or the addition of vitamins to common foods, often called fortification. The deficiency of folic acid (vitamin B9) that generally occurs during pregnancy is avoided through supplementation, therefore preventing neural tube defects in the foetus (Wright et al., 2007).

\section{Folate}

Folates are indispensable components of metabolism in all living organisms (Bekaert et $a l ., 2008)$. They play the role of donors and acceptors of one-carbon groups in one-carbon transfer reactions such as the formation of 
important biomolecules, like nucleic acids, pantothenate (vitamin B5) and amino acids. Folates are synthesized de novo in bacteria, fungi and plants. Like other vertebrates, humans fully depend only on their diet for folate supply. Being an important component of human diet, plants constitute the main source of folates. Unfortunately, most staple crops such as potato, rice, cassava and corn are relatively poor in folates; hence, in regions where these staples are the main (or sole) energy source, folate deficiency is highly prevalent (Blancquaert et al., 2014).

\section{Consequences of folate deficiency in humans}

Humans need to maintain an adequate dietary intake of folate during various stages of their lives. Folate plays an essential role in cell division, DNA synthesis and is involved in growth and development. Folate deficiency has far-reaching negative health consequences at all stages of life including neural tube defects (NTDs), anaemia, various forms of cardiovascular diseases, Alzheimer's disease and osteoporosis, all which have become pervasive health issues around the world in the 20th century. Studies have found that low dietary intake of folate increases the risk of delivering a child with several types of birth defects, particularly neural tube defects (NTD) and possibly leading to poor growth in the foetus or placenta (Fig 1).

\section{Functions of folate}

Folates are important for plant well being. Proper functioning of folate metabolism was demonstrated to be indispensable for plant development (Jabrin et al., 2003; Mehrshahi et al., 2010). Folates were reported to play important roles in signaling cascades (Stokes et al., 2013), as well as in nitrogen and carbon metabolism (Jiang et al., 2013; Meng et al., 2014).
Folate supplementation was demonstrated to improve plant biotic stress resistance (Wittek et al., 2015). Folate metabolism was shown to be differentially regulated in response to various abiotic stress conditions ( Neilson et al., 2011).

\section{Biofortification}

A large part of the world's population is still suffering a severe deficiency of folate supply. To solve this problem, folate supplementation in a form of folic acid pills was launched. Folic acid undergoes two rounds of reduction by Dihydrofolatereductase (DHFR) to be converted to the biologically active form, Tetrahydrofolate (THF). In addition to supplementation, industrial fortification of food products (e.g., flour) is a possible approach to reduce folate deficiency. However, the necessary infrastructure is often lacking in developing countries, especially in rural areas. An alternative approach to fight folate deficiency is the enhancement of folate levels in staple crops. Both molecular breeding technology and metabolic engineering can be used to create crops with enhanced micronutrient content, each with their advantages and shortcomings ( Strobbe and Straeten, 2017). However, the first one is dependent on the natural variation in germplasm of the crop of interest. Natural variation of folate content in rice (Ramos, 2010) and in potato (Goyer and Navarre, 2007) was found to be relatively low, hampering successful breeding, keeping in mind the target levels in processed food .

In several studies on the enhancement of folate levels in plants, GTPCHI or ADCS (or both), were over expressed. The approach aims at the enhancement of the metabolic flux through the biosynthetic pathway by increasing the supply of the two folate precursors-pterin and pABA. Over expression of a codon-optimized native 
GTPCHI in lettuce and E. coli GTPCHI in corn plants alone resulted in 2.1 to 8.5 -fold and 2-fold, increase in the folate level respectively ( Nunes et al., 2009). The limited success of the two attempts was ascribed to the depletion of the pABA pool. A similar trend of depletion of pABA was observed in tomato plants over expressing GTPCHI by Garza et al., (2004).

In order to overcome this obstacle, a simultaneous over expression of GTPCHI and ADCS was ventured. The approach successfully increased the total folate content up to 100 times in rice (Storozhenko et al., 2007). In rice, the over expression of $A D C S$ alone led to a decrease in total folate content.
Being an inhibitor of FPGS (Folate Polyglutamate Synthase) pABA impedes folate polyglutamylation, thus affecting folate stability and consequently its abundance. Another study on rice demonstrated that over expression of HPPK/DHPS, a gene coding for the first two enzymes of the mitochondrial part of the biosynthetic path, results in a slight increase of the folate level (Gillies et al., 2008). This result holds promise for possibility of a further increase in folate level by a combined over expression of GTPCHI, ADCS and HPPK/DHPS genes. Manipulation of the folate polyglutamylation status by altering GGH expression was also demonstrated to affect folate content.

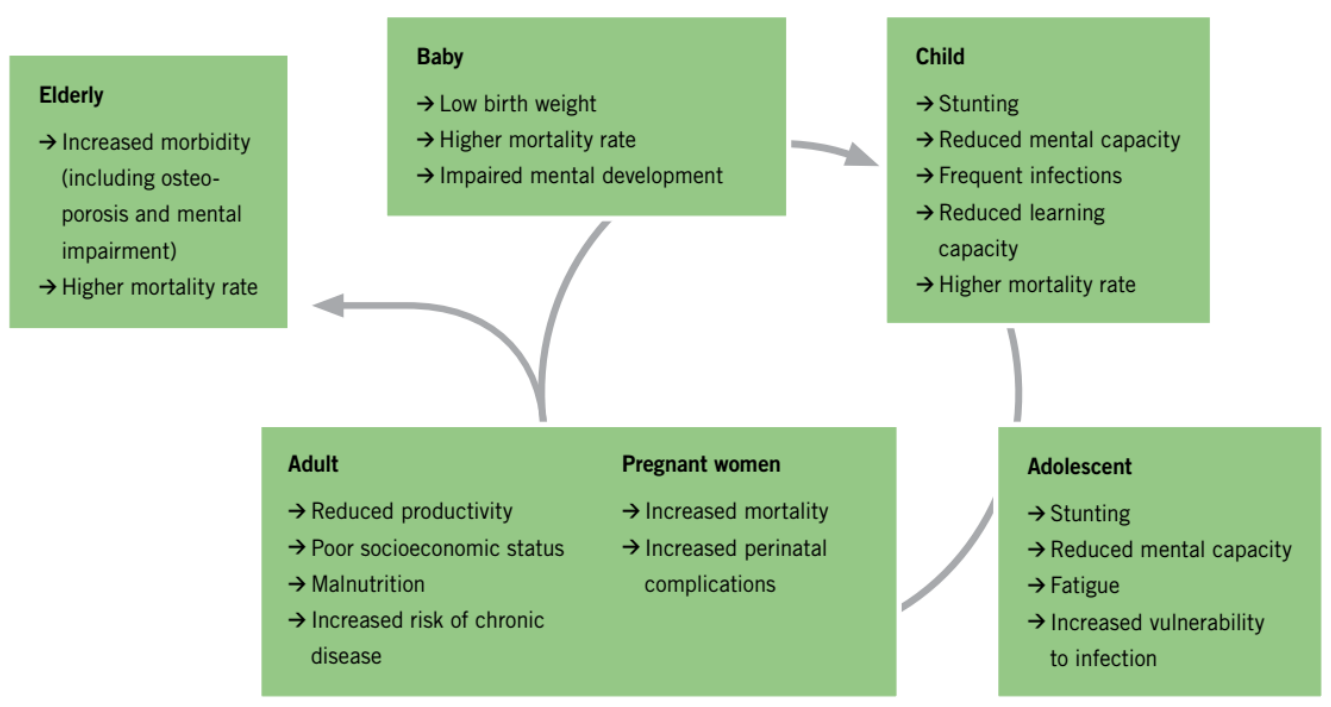

Figure.1 Health issues due to folate deficiency (Source: Adapted from ACC/SCN, 2000)

As future perspective for the enhancement of abundance and stability of the folate pool in staple crops, a combination of several approaches should be ventured. It also should be taken into account that bio fortification strategies applied may not be equally efficient for all crop species. Thus, over expression of both ADCS and GTPCHI substantially increased folate level in rice grains (Storozhenko et al., 2007). Therefore, in order to develop a successful bio fortification strategy, one should consider possible differences in the regulation of folate biosynthesis of a given plant species.

\section{References}

Bekaert, S., S.Storozhenko, P.Mehrshahi, M.J. Bennett, W.Lambert and J. F. Gregory. 2008. Folate biofortification in food plants. Tr. Plant Sci., 13: 28-35.

Gillies, S. A., S. R. McIntosh and R. J. Henry. 
2008. "A cereal crop with enhanced folate: rice transgenic for wheat HPPK/DHPS," in ComBio 2008 (Canberra, ACT; Lismore, NSW: Southern Cross Plant Science, Centre for Plant Conservation Genetics).

Godfray, H.C.J., J.R. Beddington, I.R. Crute, L. Haddad, D. Lawrence, J.F. Muir, J.Pretty, S. Robinson, S.M. Thomas and C. Toulmin. 2010. Food security: the challenge of feeding 9 billion people. Science., 327:812-818.

Goyer, A and D. A. Navarre. 2007. Determination of folate concentrations in diverse potato germplasm using a trienzyme extraction and a microbiological assay. J. Agric. Food Chem., 55: 35233528.

Jabrin , S, S. Ravanel S, B.Gambonnet, R. Douce and F. Rébeillé . 2003. One-carbon metabolism in plants. Regulation of tetrahydrofolate synthesis during germination and seedling development. Pl. Physiol., 131:1431-1439.

Jiang, L., Liu, Y., Sun, H., Han, Y., Li, J., Li, C.2013. The mitochondrial folylpolyglutamate synthetase gene is required for nitrogen utilization during early seedling development in Arabidopsis. Plant Physiol., 161: 971-989.

Kraemer, K., Monika Waelti, Saskia de Pee, Regina Moench-Pfanner, John N Hathcock,

Martin W Bloem and Richard D Semba. 2008. Are low tolerable upper intake levels for vitamin A undermining effective food fortification efforts? .Nutr. Rev., 66(9): 517-525.

Mehrshahi, P., Gonzalez-Jorge, S., Akhtar, T. A., Ward, J. L., Santoyo-Castelazo, A., and Marcus, S. E. 2010 . Functional analysis of folate polyglutamylation and its essential role in plant metabolism and development. Plant J., 64:267-279.

Meng, H., Jiang, L., Xu, B., Guo, W., Li, J., Zhu, X., 2014. Arabidopsis plastidial folylpolyglutamate synthetase is required for seed reserve accumulation and seedling establishment in darkness. PLoS ONE 9:e101905.

Neilson, K. A., Mariani, M., and Haynes, P. A. 2011. Quantitative proteomic analysis of cold-responsive proteins in rice. Proteomics., 11: 1696-1706.

Nunes, A. C., D.C. Kalkmann, and F.J. Aragao.2009. Folate biofortification of lettuce by expression of a codon optimized chicken GTP cyclohydrolase I gene. Transgen. Res.,18: 661-667.

Parengam, M., K. Judprasong, S. Srianujata, S. Jittinandana, S. Laoharojanaphand and A. Busamongko. 2010. Study of nutrients and toxic minerals in rice and legumes by instrumental neutron activation analysis and graphite furnace atomic absorption spectrophotometry. J. Food Comp. Anal., 23:340-345.

Ramos, R.A. 2010. Folate Profiling in Wild and Transgenic Rice. Nottingham: University of Nottingham.

Stokes, M. E., Chattopadhyay, A., Wilkins, O., Nambara, E., and Campbell, M. M. 2013. Interplay between sucrose and folate modulates auxin signaling in Arabidopsis. Plant Physiol., 162: 1552-1565. doi: 10.1104/pp.113.215095

Storozhenko, S., V. De Brouwer, M. Volckaert, O. Navarrete, D. Blancquaert, G.F. Zhang, et al., 2007a. Folate fortification of rice by metabolic engineering. Nat. Biotech, 25:1277-1279

Strobbe, S and D. Van Der Straeten. 2017. Folate biofortification in food crops. Curr Opin Biotechnol., 44 : 202-211.

Wittek, F., Kanawati, B., Wenig, M., Hoffmann, T., Franz-Oberdorf, K., Schwab, W., 2015. Folic acid induces salicylic aciddependent immunity in Arabidopsis and enhances susceptibility to Alternaria brassicicola. Mol. Plant Pathol., 16, 616622

Wright, E.R, Schooler JB, Ding HJ, Kieffer C, Fillmore C, Sundquist WI, Jensen GJ (2007) Electron cryotomography of immature HIV-1 virions reveals the structure of the CA and SP1 Gag shells.EMBO J 26: 2218-2226 
How to cite this article:

Aiyswaraya. K. S., R. Saraswathi, S. Ramchander, D. Uma, M. Aswin, B. N. Rithesh, P. Jeyaprakash, D. Sudhakar and Robin. S. 2020. Review on: Folate in Crop Plants. Int.J.Curr.Microbiol.App.Sci. 9(03): 2831-2836. doi: https://doi.org/10.20546/ijcmas.2020.903.326 